\title{
Model Inkuiri Terbimbing Berbantuan Laboratorium Virtual Untuk Meningkatkan Keterampilan Proses Sains
}

\author{
Ziadatul Fatimah ${ }^{1 *}$, Dedi Riyan Rizaldi ${ }^{1}$, A.Wahab Jufri ${ }^{1}$, Jamaluddin ${ }^{1}$ \\ ${ }^{1}$ Magister Pendidikan IPA, Universitas Mataram, Lombok, Indonesia
}

DOI: https://doi.org/10.29303/goescienceedu.v1i2.45

\section{Article Info}

Received : 6 Juli 2020

Revised : 15 November 2020

Accepted: 15 Desember 2020

\begin{abstract}
Abstrak: Penulisan ini bertujuan untuk mengetahui laboratorium virtual atau yang biasa disebut dengan V-lab sebagai suatu media pembelajaran yang dapat membantu peserta didikdalam meningkatkan keterampilan proses sains dalam proses pembelajaran. Jenis penelitian ini adalah penelitian kualitafif dengan teknik analisis induktif berupa pengumpulan data triangulasi, dimana teknik pengumpulan data yang bersifat menggabungkan dari berbagai teknik pengumpulan data dan sumber data yang telah ada. Data dikumpulkan melalui kegiatan kajian pustaka dari beberapa sumber, seperti buku teks dan jurnal terakreditasi. Berdasarkan kajian pustaka dapat disimpulkan bahwa V-lab merupakan suatu media berbasis komputer yang berisi simulasi kegiatan di laboratorium. Jenis V-lab berkembang sesuai dengan perkembangan zaman. V-lab juga mendukung kegiatan pembelajaran di tingkat sekolah dan perguruan tinggi dan V-lab juga memiliki kelebihan yang dapat membantu dalam proses pembelajaran dan disamping itu memiliki beberapa kelemahan.
\end{abstract}

Kata Kunci: Laboratorium Virtual; Keterampilan Proses Sains; Proses Pembelajaran

Abstract: This writing aims to determine the virtual laboratory or what is commonly referred to as the V-lab as a learning medium that can help students improve science process skills in the learning process. This type of research is qualitative research with inductive analysis techniques in the form of triangulation data collection, where data collection techniques are combining various data collection techniques and existing data sources. Data was collected through literature review activities from several sources, such as accredited textbooks and journals. Based on literature review, it can be concluded that V-lab is a computer-based media that contains simulations of activities in the laboratory. The V-lab type develops according to the times. V-lab also supports learning activities at the school and college level and V-lab also has advantages that can help in the learning process and besides that it has several weaknesses.

Keyword: Virtual Laboratory; Science Process Skills; Learning process

\section{Pendahuluan}

Inti dari sains tidak hanya tentang konten tetapi juga proses. Fisika merupakan bagian dari sains yang mempelajari gejala alam yang tidak hidup atau materi dalam lingkungan hidup ruang dan waktu, serta semua interaksi yang menyertainya. Fisika sering disebut sebagai ilmu yang paling mendasar karna setiap ilmu alam lainnya mempelajari jenis sistem materi tertentu yang mematuhi hukum fisika (Harefa, 2019). Beberapa konsep abstrak yang terdapat dalam pembelajaran fisika, menimbulkan kesulitan dalam memahami suatu materi (Arief et al., 2012). 
Dalam mempelajari ilmu fisika ada dua hal yang harus dipelajari, yaitu aspek produk (fakta, konsep, prinsip, teori, hukum) dan aspek empiris (Hidayaturrohman, 2017). Aspek empiris dalam pembelajaran di sekolah dilakukan dengan pelaksanaan praktikum. Dengan demikian, pembelajaran fisika memiliki enam keterampilan proses yang dikembangkan dalam pembelajaran, antara lain: mengamati, mengklasifikasi, mengukur, mengkomunikasikan, menyimpulkan, dan merencanakan eksperimen. Dalam melakukan kegiatan eksperimen kita membutuhkan laboratorium yang memadai baik segi kualitas maupun kuantitas yang disesuaikan dengan jumlah peserta didik. Namun demikian tidak semua sekolah memiliki laboratorium yang memadai, sehingga tidak semua konsep fisika diajarkan melalui kegiatan praktikum di laboratorium. Ketiadaan alat dan bahan sering menjadi kendala tidak dilakukannya praktikum, meskipun guru pengampu memiliki petunjuk praktikum, walaupun praktikum memegang peran penting di dalam pembelajaran IPA (Ismail, et al., 2016). Oleh karena itu sangat diperlukan kreativitas seorang guru dalam mencari alternatif bahan dan alat lain yang dapat digunakan agar praktikum tetap dapat dilaksanakan.

Alternatif pelaksanaan praktikum yang dapat dilakukan, yaitu pengembangan praktikum dengan menggunakan Virtual Lab. Laboratorium virtual (V-lab) adalah laboratorium komputasi yang dirancang agar peserta didik mampu melakukan praktikum walau tidak secara langsung. Hal ini juga mampu menghemat alat dan bahan.

Hambatan dalam praktikum dapat diatasi dengan menggunakan media pembelajaran alternatif Vlab. Virtual lab menggunakan program komputer untuk menyimulasikan serangkaian percobaan tanpa melakukan kegiatan secara langsung. V-lab dapat memperkuat kegiatan praktikum yang tidak dapat dipraktekkan secara nyata, artinya virtual lab dapat menjadi media praktikum alternatif untuk menggantikan praktikum nyata jika tidak memungkinkan untuk dilakukan. V-lab dapat mendukung peserta didik untuk mengeksplorasi dan memvisualisasikan konsep-konsep abstrak terutama dalam menggambarkan penerapan pengetahuan (Başer dan Durmuş, 2010).

\section{Metode}

Metode yang digunakan dalam penulisan artikel ini adalah metode deskriptif kualitatif dengan pendekatan post-positivisme. Pendekatan ini mengutamakan fenomena sosial yang dikonstruksi sebagai interpretasi oleh individu dan cenderung bersifat tidak tetap dan situasional (Sugiyono, 2013).
Pendekatan ini dilakukan dengan mengumpulkan data terutama data verbal melalui kajian pustaka, dan kemudian mengolahnya secara analisis induktif yang merupakan pengumpulan data triangulasi, dimana teknik pengumpulan data yang bersifat menggabungkan dari berbagai teknik pengumpulan data dan sumber data yang telah ada (Sugiyono, 2010).

Langkah-langkah dalam penulisan artikel ini antara lain: 1) Mengidentifikasi permasalah yang akan menjadi bahan kajian, 2)merumuskan masalah, 3) menentukan tujuan, 3) menentukan metode untuk mengumpulkan data, 4) melakukan kajian pustaka dari berbagai sumber, 5) memilih prosedur analisis data, dan 6) menarik kesimpulan (Setyosari, 2013).

\section{Hasil dan Pembahasan}

\section{Laboratorium Virtual}

Laboratorium biasanya didefinisikan sebagai tempat eksperimen dalam melakukan pengujian serta menganalisis dan tempat melakukan pengamatan, atau praktikum. Laboratorium yang berada di sekolah adalah unit penunjang akademik berdasarkan metode keilmuan tertentu dalam rangka melaksanakan pendidikan. Laboratorium tidak hanya berkaitan dengan alat-alat tetapi laboratorium yang sudah berkembang dalam dunia pendidikan terbagi menjadi laboratorium real dan laboratorium virtual. Laboratorium Virtual biasa disebut dengan Virtual Laboratory atau V-Lab.

Hermansyah, et al., (2015) menyatakan bahwa laboratorium virtual merupakan suatu media berbasis komputer yang berisi simulasi kegiatan di laboratorium. Laboratorium virtual dibuat untuk menggambarkan reaksi-reaksi yang mungkin tidak dapat terlihat pada keadaan nyata. Artinya sesuatu yang tidak nampak seperti contohnya radiasi benda hitam dapat kita gambarkan dalam sebuah simulasi, sehingga dalam proses pembelajaran peserta didik lebih memahami konsep dari radiasi benda hitam. Dengan format tampilan berbasis web cukup membantu peserta didik untuk dapat mengikuti praktikum secara mandiri (Puspita, 2008).

Laboratorium virtual dikembangkan agar tercipta lingkungan yang interaktif dalam proses pembelajaranyang merupakan sistem pendukung dalam proses praktikum yang berjalan secara konvensional (Jaya, 2012). Pembelajaran dengan media laboratorium virtual mampu meningkatkan motivasi belajar peserta didik dan dengan bantuan media laboratorium virtual, guru lebih berperan sebagai fasilitator pembelajaran sehingga pembelajaran lebih efektif dan efisien.Pembelajaran dengan media laboratorium virtual sangat berpengaruh dalam meningkatkan penguasaan konsep (Billah dan 
Widiyatmoko, 2018). Media pembelajaran lab virtual dapat memvisualisasikan konsep abstrak menjadi lebih konkret sehingga tujuan pembelajaran dan proses belajar menjadi lebih bermakna. Dengan pembelajaran yang bermakna, peserta didik akan mencapai hasil belajar yang lebih optimal atau lebih baik daripada sebelum.

\section{Jenis Laboratorium Virtual}

Kualitas proses dan hasil belajar fisika ditentukan oleh banyak faktor, salah satunya adalah ketersediaan sarana praktikum (Gunawan et al., 2017). Kegiatan praktikum yang biasanya dilakukan di laboratorium merupakan hal yang penting dalam pembelajaran fisika, karena aspek produk, proses, dan sikap peserta didik dapat lebih dikembangkan. Namun tidak semua percobaan dapat dilakukan, bukan hanya karena ketiadaan alat, tetapi juga dikarenakan karakteristik percobaan itu sendiri yang melibatkan proses dan konsep-konsep abstrak, sehingga diperlukan sebuah alternatif agar kegiatan percobaan tetap dapat dilakukan. Media yang dapat digunakan terdiri dari berbagai jenis media seperti gambar, video, dan animasi. Ketiga media visual tersebut disusun dalam bentuk laboratorium virtual. Media pembelajaran berupa laboratorium virtual yang dibuat dapat mempermudah peserta didik dalam memahami konsep-konsep fisika. Media ini akan menampilkan konsep-konsep fisika beserta aplikasinya dalam kehidupan sehari-hari sehingga peserta didik akan lebih mudah memahami materi yang diajarkan. Selain itu, media ini akan membuat pelajaran fisika menjadi lebih menarik sehingga peserta didik menjadi lebih semangat dalam belajar dan tidak menganggap pelajaran fisika itu membosankan.

Penelitian terdahulu yang dilakukan oleh Gunawan, et. al., (2015) membuktikan bahwa model pembelajaran berbantuan media virtual berpengaruh positif terhadap penalaran logis dan pengembangan kemampuan logika. Hal ini nantinya akan sangat membantu peserta didik untuk mengembangkan kemampuan kognitif dan kreativitas. Jaya (2012) menyatakan bahwa Laboratorium virtual dapat dibedakan menjadi dua tipe utama yaitu laboratorium berdasarkan simulator dan laboratorium yang berbasis pada peralatan hardware yang nyata baik 2-D maupun 3D. Tipe 2-D didasarkan pada set model perangkat lunak yang merupakan objek atau sistem dalam tingkat abstraksi tertentu, sedangkan tipe 3-D mencakup sebagian besar kualitas jenis pertama dan memungkinkan pendekatan ini untuk yang klasik. Dengan seiringnya perkembangan zaman V-lab berkembang menjadi 4-D (Define, Design, Develop, and Disseminate) (Thiagarajan, et. al.,1974). Ketiga jenis V-lab tersebut memiliki kelebihan dan kelemahan masing- masing dan terus diperbaharui sesuai dengan kebutuhan guru untu memberikan pembelajaran yang bersifat bermakna kepada peserta didik dalam segi praktikum khususnya pada mata pelajara IPA (biologi, fisika dan kimia).

\section{Laboratorium Virtual untukMendukung Kegiatan Pembelajaran}

Proses pembelajaran akan berhasil jika adanya faktor yang saling mempengaruhi motivasi belajar peserta didik selain dari diri sendiri juga diperoleh dari lingkungan belajar seperti guru dan sumber belajar. Jika keduanya saling mempengaruhi akan menghasilkan suatu proses pembelajaran yang bermakna dan hasil belajar akan menjadi meningkat. Belajar yang bermakna dan menyenangkan mampu mengasah kemampuan berpikir peserta didik dengan menggunakan laboratorium virtual dalam proses pembelajaran. Laboratorium virtual ini bisa lebih mepermudah peserta didik untuk melakukan praktikum dan memahami konsep-konsep fisika. Sehingga dapat meningkatkan penguasaan konsep dan kemampuan berpikir peserta didik. Pernyataan tersebut sesuai dengan penelitian yang dilakukan oleh Hermansyah, et. al., (2015) bahwa proses belajar mengajar dengan menggunakan laboratorium virtual dapat merangsang peserta didik untuk lebih aktif dalam mengikuti kegiatan belajar mengajar. Suasana didalam kelas menjadi lebih hidup dan peserta didik lebih bersemangat dalam mengikuti proses pembelajaran, karena dalam proses pembelajaran peserta didik dapat mengembangkan kreativitas mereka masing-masing dan terlihat lebih aktif, hal ini menunjukkan peserta didik tertarik terhadap penggunaan laboratorium virtual.

Penelitian lain yang dilakukan oleh Gunawat, et. al., (2019) menunjukkan bahwa pembelajaran inkuiri terbimbing dengan bantuan lab virtual memberikan efek yang signifikan pada keterampilan proses sains. Rata-rata keterampilan proses sains pada pembelajaran inkuiri terbimbing lebih tinggi daripada konvensional. Inkuiri terbimbing dengan bantuan lab virtual mampu meningkatkan keaktifan peserta didik dan mampu mempersiapkan peserta didik dalam melakukan percobaan secara independen dengan bimbingan guru. Kedepannya pembelajaran inkuiri terbimbing dengan bantuan lab virtual ini bisa digunakan untuk mengukur keterampilan berpikir abad 21.

Kelas ekperimen dengan perlakuan virtual laboratorium memiliki sikap lebih positif dibandingkan kelas kontrol dengan laboratorium biasa. Virtual laboratorium meningkatkan minat peserta didik dan membuat pelajaran jadi menyenangkan serta lebih bermakna sehingga konsep fisika yang abstrak jadi lebih mudah dipahami. Laboratorium virtual bertindak 
sebagai jembatan untuk memahami hubungan antara konsep dan peristiwa kehidupan nyata (Asıksoy dan Islek, 2017).

\section{Kelebihan dan Kekurangan Lab Virtual dalam Proses Pembelajaran}

Pembelajaran lab virtual mampu mereduksi miskonsepsi yang dialami peserta didik, karena lab virtual bisa secara langsung memviasualisasikan konsep yang abstrak.Penggunaan virtual lab dalam pembelajaran memiliki beberapa kelebihan diantaranya: (1) memungkinkan peserta didik untuk menghasilkan karya eksperimen yang lain karena efektif dari segi waktu dan biaya; (2) memungkinkan siswa untuk memperoleh visualisasi pada tingkat makroskopik, submikroskopik, dan tingkat simbolik; (3) memberikan presentasi dinamis dari dunia partikel submikro; (4) berkontribusi pada pemahaman yang lebih baik dari kandungan kimia; dan (5) alat motivasi yang kuat. (Herga, et.al., 2014)

Meski memiliki kelebihan simulasi laboratorium interaktif ini juga tetap memiliki kekurangan yang masih perlu dicarikan solusi pemecahan masalahnya, yaitu adanya keterbatasan kemampuan komputer dalam hal mengatasi permasalahan yang dihadapi oleh peserta didik secara individual dalam proses pembelajaran. Hal lainnya, program komputer tidak dapat menjangkau aspek psikomotorik dari ranah pembelajaran sehingga penguasaan keterampilan praktis peserta didik perlu diarahkan tersendiri selama pembelajaran berlangsung. Namun demikian, jika mencermati dari esensi praktikum secara garis besar sebenarnya representasi praktikum melalui simulasi laboratorium interaktif ini, telah cukup terwakili. Hal ini dikarenakan oleh adanya beberapa keterampilan pragmatis seperti keterampilan mengamati dan menganalisis data yang merupakan salah satu bagian terpenting yang dapat diperoleh dari simulasi laboratorium interaktif tersebut.

\section{Kesimpulan}

Berdasarkan hasil kajian data dan pembahasan, dapat disimpulan bahwa V-lab merupakan suatu media berbasis komputer yang berisi simulasi kegiatan di laboratorium. Jenis V-lab berkembang sesuai dengan perkembangan zaman. V-lab juga mendukung kegiatan Belajar-mengajar di tingkat sekolah dan perguruan tinggi, dan V-lab juga memiliki kelebihan yang dapat membantu dalam proses pembelajaran dan disamping itu memiliki beberapa kelemahan.

\section{Ucapan Terimakasih}

Penulis mengucapkan banyak terimakasih kepada bapak Prof. Dr. A. Wahab Jufri, M.Sc. dan Dr. Jamaluddin, M.Pd. selaku dosen mata kuliah Belajar dan Pembelajaran IPA yang telah banyak membantu dalam penyusunan artikel ilmiah ini.

\section{Referensi}

Arief, M. K., Handayani, L., \& Dwijananti, P. (2012). Identifikasi Kesulitan Belajar Fisika Pada Siswa Rsbi : Studi Kasus Di Rsmabi Se Kota Semarang. UPEJ (Unnes Physics Education Journal), 1(2). https://doi.org/10.15294/upej.v1i2.1354

Asıksoy, G., Islek, D. (2017). The Impact of the Virtual Laboratory on Students' Attitudes in a General Physics Laboratory. International Journal of Online and Biomedical Engineering. Vol.13 (4): 20-28, from https://onlinejour.journals.publicknowledgeproj ect.org/index.php/ijoe/article/view/6811/4397.

Başer, M., dan Durmuş, S. (2010). The effectiveness of computer supported versus real laboratory inquiry learning environments on the understanding of direct current electricity among preservice elementary school teachers. EURASIA Journal of Mathematics, Science and Technology Educatio. Vol.6 (1): 47-61, from www.ejmste.com/pdf-75227-12029?

filename $=$ The $\%$ 20Effectiveness $\% 20$ of.pdf.

Billah, A., dan Widiyatmoko, A. (2018).The Development of Virtual Laboratory Learning Media for the Physical Optics Subject. Jurnal Ilmiah Pendidikan Fisika Al-Biruni. Vol.7 (2): 153$160 . \quad$ DOI: 10.24042/ jipfalbiruni.v7i2.2803.

Gunawan, G., Harjono, A., \& Sahidu, H. (2017). Studi Pendahuluan Pada Upaya Pengembangan Laboratorium Virtual bagi Calon Guru Fisika. Jurnal Pendidikan Fisika Dan Teknologi, 1(2), 140. https:// doi.org/10.29303/jpft.v1i2.250

Gunawan, G., Harjono, A., Hermansyah, H., \& Herayanti, L. (2019). Guided Inquiry Model Through Virtual Laboratory To Enhance Students' Science Process Skills On Heat Concept. Jurnal Cakrawala Pendidikan, 38(2), 259-268. doi:https://doi.org/10.21831/cp.v38i2.23345.

Gunawan, Harjono, A., dan Sutrio. (2015). Multimedia Interaktif Dalam Pembelajaran Konsep Listrik Bagi Calon Guru. Jurnal Pendidikan Fisika dan Teknologi 1, (1): 9-14, from DOI: http://dx.doi.org/10.29303/jpft.v1i1.230.

Harefa, A. R. (2019). Peran Ilmu Fisika dalam 
Kehidupan Sehari-hari. Jurnal Warta, 60(April), 91-96.

Herga, N. R., Grmek, M. I., dan Dinevski, D. (2014). Virtual laboratory as an element of visualization when teaching chemical contents in science class. TOJET: The Turkish Online Journal of Educational Technology. Vol. 13 (4):157-165, from https://eric.ed. gov/?id=EJ1043246.

Hermansyah., Gunawan., Herayanti, L. (2015). Pengaruh Penggunaan Laboratorium Virtual terhadap Penguasaan Komsep dan Kemampuan Berpikir Kreatif Peserta didik Pada Materi Getaran dan Gelombang. Jurnal Pendidikan Fisika dan Teknologi. Vol. 1 (2): 97-102, from DOI: http://dx.doi.org/10.29303/jpft. v1i2.242.

Hidayaturrohman, R. (2017). Pengembangan Bahan Ajar Interaktif Fisika Berwawasan SETS untuk Meningkatkan Kemampuan Berpikir Kritis Siswa. Seminar Nasional Pendidikan Fisika, 2(September), 1-2. https://jurnal.unej.ac.id/index.php/fkipepro/article/view/6242/4949

Ismail, I., Permanasari, A., Setiawan, W. (2016). Efektivitas Virtual Lab Berbasis STEM dalam Meningkatkan Literasi Sains Siswa dengan Perbedaan Gender. Jurnal Inovasi PendidikanIPA. Vol 2 (2): 190 - 20. DOI: 10.21831/jipi.v2i2.8570.

Jaya, H. (2012). PengembanganLaboratorium Virtual untuk Kegiatan Praktikum dan Memfasilitasi Pendidikan Karakter Di SMK. Jurnal Pendidikan Vokasi, Vol. 2 (1): 81-90. DOI: 10.21831/ipv.v2i1.1019.

Puspita, R. (2008). Sistem Informasi Aplikasi Virtual Lab Pada Laboratorium Sistem Informasi Universitas Gunadarma. Proceeding, Seminar Ilmiah Nasional Komputer dan Sistem Intelijen (KOMMIT 2008) Auditorium Universitas Gunadarma, Depok, 20-21 Agustus 2008. ISSN : 1411-6286: 190-198.

Setyosari, P. (2013). Metode Penelitian Pendidikan dan Pengembangan. Jakarta: Prenada Media Group.

Sugiyono. (2010). Metode Penelitian Administratif. Bandung: Alfabeta.

Sugiyono. (2013). Metode Penelitian Pendidikan: Pendekatan Kuantitatif, Kualitatif, dan RED. Bandung: Penerbit Alfabeta.

Thiagarajan, S., Semmel, D.S., dan Semmel, M.I. (1974). Instructional Development for Training Teachers of Expectional Children. Minneapolis, Minnesota: Leadership Training Institute/ Special Education, University of Minnesota. 